Editorial

\title{
Power Transformer Diagnostics, Monitoring and Design Features
}

\author{
Issouf Fofana ${ }^{1, *(1)}$ and Yazid Hadjadj ${ }^{2}$ \\ 1 Aging of Power Network Infrastructure (ViAHT), Université du Québec à Chicoutimi, \\ Chicoutimi, QC G7H 2B1, Canada \\ 2 Measurement Science and Standards, National Research Council (NRC), \\ Ottawa, ON K1A 0R6, Canada; yazid.hadjadj@nrc-cnrc.gc.ca \\ * Correspondence: ifofana@uqac.ca; Tel.: +1-418-545-5011
}

Received: 12 October 2018; Accepted: 13 November 2018; Published: 22 November 2018

\section{Introduction}

The reliability of the power grid system directly contributes to the economic well-being and the quality of life of citizens in any country. In the electric power distribution and transmission systems, it is essential that key equipment such as transformers function properly for many years. In these important equipment, the Achilles' heel is the insulation system, i.e., (a) insulation between the high voltage (HV) winding and the tank; (b) insulation between the HV and the low voltage (LV) windings; and (c) inter-phase insulation. Over the past decade, various types of insulating materials have been introduced in these machines. Assessment methods have allowed monitoring their conditions with the aim of providing the basic information required for power grid operators and maintenance planners to understand the issues related to aging. Also, aging indicator indices have been the aim of a large number of investigations.

Many transformers around the world are now approaching the end of their theoretical design life. In this context, managing the aging population of power transformers has become one of the most critical issues today's maintenance planners and engineers have to face. With increasing age, there are potential risks of extremely high monetary losses due to unexpected failures and outages. A simple solution would be to replace all aging and risky transformers at once with new ones. Such an approach is obviously not a fiscally realistic solution. The main objectives are: to extend their service life and optimize their performance through increased availability. For these reasons, transformer life management in the past few decades has gained an ever-increasing interest due to economic and technical reasons. The greatest challenges are related to the need for methods to assess the condition and life expectancy along with the improvement of transformer efficiency by noble designs and/or application of new materials.

The special issue was focused on theoretical and practical developments with a special emphasis on new research and development $(R \& D)$ trends in transformer designs/diagnostics and maintenance. Additionally, today, "sustainable development" has become a world-wide concept for the scientific community. The focus is now on harvesting renewable resources instead of fossil fuels, and using environmentally friendly materials. In this context, new materials are emerging for the design of electrotechnical insulation systems including biodegradable insulating materials, with properties that are at least equal to conventional materials. Esters with excellent high temperature performance, enhanced fire safety, increased environmental protection and increased moisture tolerance are gaining importance. Some aspects regarding the application of biodegradable fluids in these important machines were therefore also of particular interest. Listed hereafter, among others, were some of the topics of interest considered: 
- New or emerging diagnostic/monitoring technologies;

- Mineral oils of improved characteristics, additives;

- Nanofluids and synthetic/vegetable dielectric liquids;

- New materials for transformers;

- Transformer life management.

\section{An Outlook of the Special Issue}

This special issue from Energies, has been successfully organized with the support extended by the editorial team of the journal and the MDPI publishing team. The average processing time of the articles was noted to be 75.67 days. The guest editor is very much grateful to all reviewers for reviewing and revising the manuscripts. Devoting their valuable time to reviewing papers is essential for upholding the voluntary peer review process and is highly commendable. Their constructive comments and suggestions to the authors and confidential reports to the editors ensured that the high standard of this journal is maintained.

Response to our call was excellent, with the following statistics:

- Submissions: (21);

- Publications: (12);

- Rejections: (9);

- Article types: review articles (3); research articles (9);

- Authors' geographical distribution (published papers):

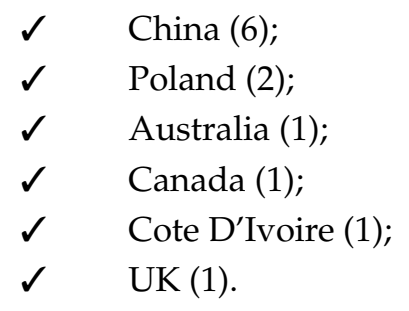

The summary of the articles published in this issue is discussed in the subsequent sections of this editorial.

\section{A Review of the Special Issue}

A number of articles involve several subjects about power transformer diagnostics, insulation characterization, and new materials for transformers have been published in this issue.

Sun et al. [1] proposed a new decision-making model for transformer condition assessment. The new model integrates the merits of fuzzy set theory, game theory and modified evidence combination extended by D numbers. It was shown that compared to the evidential reasoning-based method, the final evaluation result of the presented method could clearly show the health condition of the transformer.

Li et al. [2] introduced a new intelligent sensor for ultra-high-frequency (UHF) partial discharge (PD) online monitoring in power transformers. The statistical characteristic quantities of UHF PD signals were acquired by means of a new method, namely the level scanning method which is the base of the intelligent sensor. The experimental results of the proposed sensor under laboratory conditions showed that the intelligent sensor could accurately acquire statistical characteristic quantities of the UHF PD signal, which indicated that the proposed intelligent sensor was qualified for UHF PD online monitoring.

In recent years, a lot of research has been directed towards environmentally friendly insulating liquids, as an alternative to mineral oils. However, as the chemical compositions of these fluids are very different than those for mineral oils, new specification standards for non-mineral oils have been 
produced. In this Issue a comparison study of streamer propagation and breakdown between Ester liquids and mineral oil was conducted by Rozga [3].

The work was focused on the comparison of light waveforms registered using the photomultiplier technique. The results indicated that both esters demonstrated a lower resistance against the appearance of fast energetic streamers than mineral oil.

Xiang et al. [4] also presented a comparison study of the formation of dissolved gases in mineraland vegetable- insulating oils. The authors used four interpretation dissolved gas analysis (DGA) methods and they confirmed that the diagnosis methods developed for mineral oil were not suitable for the diagnosis of electrical and thermal faults in vegetable-insulating oils and needed some modification. Thus, the proposed modified Duval Triangle method based on Duval Triangle 3 is used to diagnose the thermal and electrical fault of FR3 oil and camellia oil through redefining zone boundaries of Duval Triangle 1 and obtains more accurate diagnostic results. Furthermore, the generation mechanisms of gases in vegetable oils have been interpreted by means of unimolecular pyrolysis simulation and the reaction enthalpies calculation. Bandara et al. [5] investigated the performance of natural ester (NE) in moisture-rich environments. They have compared the aging behaviour of NE and mineral oil impregnated pressboard (PB) insulation. While NE insulating oil possesses resistance to the aging of $\mathrm{PB}$ insulation, it was noted that the acidity and the color of NE oils could increase rapidly due to the pronounced hydrolytic degradation in a moisture rich environment. On the other hand, dielectric dissipation factor (DDF), viscosity, and the dielectric breakdown voltage, were suitable for the assessment of the overall condition of NE insulation oils.

Wang et al. [6] have introduced a new aspect for overload capability assessment of power transformers. In their article they estimated the running time of a power transformer under overload conditions by means of the hot-spot temperature. The overloading probability was then fitted by the Weibull distribution, in which the desired parameters were computed according to a new proposed objective function.

Wang et al. [7] investigated the influence of initial moisture contents in oil impregnated paper of the condenser bushing. The results of their experience indicated that the initial moisture content has appreciable impact on the degradation of the insulation paper during the initial aging period. They found that it was possible to evaluate the aging degree and moisture of solid insulation of bushing by doing some analysis of the DDF.

As discussed earlier, this Special Issue also reported on three comprehensive surveys [8-10]. A snapshot look at some significant developments and applications over the last decades were addressed and future research hotspots and notable research topics were also discussed for the benefit of researchers. Two reviews about physicochemical and electrical-based diagnostic techniques for insulation condition assessment were presented by Fofana et al. [8,9] considering 149 and 137 references, respectively. In the article written by $\mathrm{N}^{\prime}$ cho et al. [8], in addition to traditional diagnostic techniques, some modern physicochemical diagnostic techniques such as Fourier transform infrared spectroscopy (FTIR), UV/visible spectroscopy, turbidity analysis were introduced. The benefits of using alternative insulating materials has also been discussed. In [9], Fofana and Hadjadj reported detailed descriptions and interpretations of traditional and advanced electrical diagnostic techniques. Online condition monitoring of power transformers were also discussed. Finally, the authors presented some suggestions/recommendations related to the nature of the defect or fault in the power transformer's main component. The third review article by Tang et al. [10], reported on the space charge behavior in an oil-paper insulation system. Research progress during the last two decades was critically reviewed considering 62 references. The influences of applied voltage, temperature, moisture content and aging on the space charge evolution in the oil-paper insulation has been demonstrated. This review ends with future work on space charge measurement of oil-paper insulation materials.

Sikorski et al. [11] reported on important aspects regarding PDs monitoring on power transformers. They reported that PDs activity under thermal runaway should be associated with moisture changes in the insulating system. 
Zou et al. [12] proposed a new way for assessing the aging condition of oil-paper insulation based on confocal laser Raman spectroscopy (CLRS) in conjunction with principal component analysis (PCA) and multi-classification support vector machine (SVM). The investigations were performed in laboratory conditions using 160 oil-paper insulation samples and the approach validated with 105 oil-paper insulation samples. The results reported demonstrated the feasibility of using CLRS in conjunction with the PCA-SVM technique for aging stage assessment of oil-paper insulation.

\section{Closing Remarks}

The contributions in this Special Issue discussed a wide range of subjects relevant to power transformer monitoring and applications. Power transformers are amongst the costliest equipment in the power grid. Maintaining these important machines in a pristine condition is therefore very important for power grid reliability. Even though the articles reported very interesting applications and monitoring techniques developed thus far, there are still many gaps to close to improve service reliability.

Combined with the ever-increasing global demand for energy, it has become essential to find new solutions, based on the ability to properly diagnose the condition of transformers and to delay/slow down the aging process. According to Victor Hugo "what to foresee is the unforeseen". An important strategy consists in reducing the risk of failures through remote monitoring and optimized maintenance. However, to be cost-effective, this requires an accurate assessment of the condition of the transformers. The general trend towards smart-grids, digital systems and the continued reduction in the cost of these technologies, combined with the existence of a communications infrastructure in a growing number of facilities, will facilitate the implementation of monitoring technologies.

In today's grids, power transformers must withstand not only transients due to lightning, and switching operations with load changes or fault occurrences but also the increase penetration of renewable energy sources/plug-in vehicles. These machines have a common denominator; they consist mainly of a large core of magnetic sheets around which are wound insulated conductors immersed in oil. However, their design philosophy and manufacture (based on years of R\&D and experience) require a considerable number of calculations, verifications and precautions. However, in a world where everything is changing rapidly, the key strategy must be based on continuous improvement of every aspect of the manufacturing elements. Innovative strategies/concepts that can improve the quality of these important machines are therefore required.

Author Contributions: The authors contributed equally to this work.

Funding: This research received no external funding.

Acknowledgments: Issouf Fofana is grateful to the MDPI Publisher for the invitation to act as the guest editor of this special issue and is indebted to the editorial staff of "Energies" for their kind cooperation, patience and committed engagement. The guest editor would also like to thank the authors for submitting their excellent contributions to this special issue. Thanks is also extended to the reviewers for evaluating the manuscripts and providing helpful suggestions.

Conflicts of Interest: The authors declare no conflicts of interest.

\section{References}

1. Sun, L.; Liu, Y.; Zhang, B.; Shang, Y.; Yuan, H.; Ma, Z. An Integrated Decision-Making Model for Transformer Condition Assessment Using Game Theory and Modified Evidence Combination Extended by D Numbers. Energies 2016, 9, 697. [CrossRef]

2. Li, J.; Li, X.; Du, L.; Cao, M.; Qian, G. An Intelligent Sensor for the Ultra-High-Frequency Partial Discharge Online Monitoring of Power Transformers. Energies 2016, 9, 383. [CrossRef]

3. Rozga, P. Streamer Propagation and Breakdown in a Very Small Point-Insulating Plate Gap in Mineral Oil and Ester Liquids at Positive Lightning Impulse Voltage. Energies 2016, 9, 467. [CrossRef]

4. Xiang, C.; Zhou, Q.; Li, J.; Huang, Q.; Song, H.; Zhang, Z. Comparison of Dissolved Gases in Mineral and Vegetable Insulating Oils under Typical Electrical and Thermal Faults. Energies 2016, 9, 312. [CrossRef] 
5. Bandara, K.; Ekanayake, C.; Saha, T.; Ma, H. Performance of Natural Ester as a Transformer Oil in Moisture-Rich Environments. Energies 2016, 9, 258. [CrossRef]

6. Wang, C.; Wu, J.; Wang, J.; Zhao, W. Reliability Analysis and Overload Capability Assessment of Oil-Immersed Power Transformers. Energies 2016, 9, 43. [CrossRef]

7. Wang, Y.; Xiao, K.; Chen, B.; Li, Y. Study of the Impact of Initial Moisture Content in Oil Impregnated Insulation Paper on Thermal Aging Rate of Condenser Bushing. Energies 2015, 8, 14298-14310. [CrossRef]

8. N'cho, J.S.; Fofana, I.; Hadjadj, Y.; Beroual, A. Review of Physicochemical-Based Diagnostic Techniques for Assessing Insulation Condition in Aged Transformers. Energies 2016, 9, 367. [CrossRef]

9. Fofana, I.; Hadjadj, Y. Electrical-Based Diagnostic Techniques for Assessing Insulation Condition in Aged Transformers. Energies 2016, 9, 679. [CrossRef]

10. Tang, C.; Huang, B.; Hao, M.; Xu, Z.; Hao, J.; Chen, G. Progress of Space Charge Research on Oil-Paper Insulation Using Pulsed Electroacoustic Techniques. Energies 2016, 9, 53. [CrossRef]

11. Sikorski, W.; Walczak, K.; Przybylek, P. Moisture Migration in an Oil-Paper Insulation System in Relation to Online Partial Discharge Monitoring of Power Transformers. Energies 2016, 9, 1082. [CrossRef]

12. Zou, J.; Chen, W.; Wan, F.; Fan, Z.; Du, L. Raman Spectral Characteristics of Oil-Paper Insulation and Its Application to Ageing Stage Assessment of Oil-Immersed Transformers. Energies 2016, 9, 946. [CrossRef]

(C) 2018 by the authors. Licensee MDPI, Basel, Switzerland. This article is an open access article distributed under the terms and conditions of the Creative Commons Attribution (CC BY) license (http://creativecommons.org/licenses/by/4.0/). 